\title{
Structural Investigation of a Self-Cross-Linked Chitosan/Alginate Dialdehyde Multilayered Film with in Situ QCM-D and Spectroscopic Ellipsometry
}

\author{
Huang, Junhao; Moghaddam, Saeed Zajforoushan; Thormann, Esben
}

Published in:

ACS Omega

Link to article, DOI:

10.1021/acsomega.8b03145

Publication date:

2019

Document Version

Publisher's PDF, also known as Version of record

Link back to DTU Orbit

Citation (APA):

Huang, J., Moghaddam, S. Z., \& Thormann, E. (2019). Structural Investigation of a Self-Cross-Linked

Chitosan/Alginate Dialdehyde Multilayered Film with in Situ QCM-D and Spectroscopic Ellipsometry. ACS Omega, 4(1), 2019-2029. https://doi.org/10.1021/acsomega.8b03145

\section{General rights}

Copyright and moral rights for the publications made accessible in the public portal are retained by the authors and/or other copyright owners and it is a condition of accessing publications that users recognise and abide by the legal requirements associated with these rights.

- Users may download and print one copy of any publication from the public portal for the purpose of private study or research.

- You may not further distribute the material or use it for any profit-making activity or commercial gain

- You may freely distribute the URL identifying the publication in the public portal 


\title{
Structural Investigation of a Self-Cross-Linked Chitosan/Alginate Dialdehyde Multilayered Film with in Situ QCM-D and Spectroscopic Ellipsometry
}

\author{
Junhao Huang, Saeed Zajforoushan Moghaddam, ${ }^{\circledR}$ and Esben Thormann* \\ Department of Chemistry, Technical University of Denmark, Kemitorvet 206, 2800 Kgs. Lyngby, Denmark
}

Supporting Information

\begin{abstract}
A chitosan/alginate dialdehyde multilayered film was fabricated using the layer-by-layer assembly method. Besides electrostatic interaction that promotes alternate adsorption of the oppositely charged polyelectrolytes, the Schiff base reaction between the amine groups on chitosan and the aldehyde groups on alginate dialdehyde provides a covalently cross-linked film, which after reduction by sodium cyanoborohydride is stable under both acidic and alkaline conditions. Moreover, the cross-linked film is responsive to changes in $\mathrm{pH}$ and addition of multivalent salts. The structural properties of the multilayered film such as thickness, refractive index, and water content were examined using simultaneous quartz crystal microbalance with dissipation monitoring and spectroscopic ellipsometry.
\end{abstract}

\section{INTRODUCTION}

Layer-by-layer (LbL) assembly is a facile and versatile method to fabricate polymer-coated surfaces with tailored properties. ${ }^{1-4}$ In most systems, the buildup of the multilayered film is based on alternate adsorption of oppositely charged polymers through electrostatic attraction. ${ }^{5-7}$ The present study focuses on polysaccharide-based multilayered films containing chitosan (CHI) and alginate (ALG). ALG is chiefly extracted from brown seaweeds and is composed of guluronic $(G)$ and mannuronic (M) acid units forming regions of M-blocks, Gblocks, and blocks of alternating sequence (MG) (Scheme 1). ${ }^{8,9} \mathrm{CHI}$, as one of the few available cationic polysaccharides, consists of glucosamine and $\mathrm{N}$-acetylglucosamine (Scheme 1) and is obtained through partial deacetylation of chitin. ${ }^{10-12}$ Owing to their intrinsic biocompatibility and tunable chemical structures, CHI/ALG multilayered films have been extensively investigated as a promising coating material for different biomedical applications ranging from tissue engineering to targeted drug delivery. ${ }^{13-16}$ In addition, it has been demonstrated that parameters such as $\mathrm{pH}$, ionic strength, polymer molecular weight, and polymer concentration can significantly affect the buildup process. ${ }^{17-25}$ Careful adjustment of these parameters then allows one to tune the functional properties of the coating such as permeability and bioadhesion. $^{26-29}$ The buildup process and properties of $\mathrm{CHI} /$ ALG multilayered films have been widely investigated using different methods, such as quartz crystal microbalance with dissipation monitoring (QCM-D), IR spectroscopy, atomic force microscopy (AFM), transmission electron microscopy, confocal laser scanning microscopy, scanning electron microscopy, and molecular dynamics simulation. ${ }^{23-25,30-34}$
Although electrostatic attraction is the main driving force for the buildup of polysaccharide multilayered films, it also limits their stability. For instance, changes in $\mathrm{pH}$ can disrupt the charge neutrality condition within the film, which can give rise to uncontrolled swelling and instantaneous disintegration of the film. ${ }^{17,35}$ To overcome this problem, the assembled film is then chemically cross-linked using cross-linking agents such as glutaraldehyde, genipin, carbodiimide, and diazonium diphenylamine. ${ }^{18,36-38}$ Use of such cross-linkers, however, has several shortcomings. For instance, it has been suggested that cross-linking mostly occurs in the outer layer of the film because of diffusion barriers. ${ }^{39,40}$ In some cases, it has also been found that the physiochemical properties of the film such as wettability were notably changed. ${ }^{41,42}$ On the other hand, incorporation of linker molecules, such as glutaraldehyde, not only modifies the film structure and physical properties but also negatively affects its biocompatibility and thus limits the range of applications. ${ }^{43-45}$

It has been demonstrated that partial oxidation of alginate (as well as other polysaccharides) using periodate causes a ring-opening reaction that produces two aldehyde groups. ${ }^{46,47}$ The introduced aldehyde groups on alginate dialdehyde (ADA) can then interact with the amine groups on $\mathrm{CHI}$ to form covalent imine bonds $(\mathrm{R}-\mathrm{CH}=\mathrm{N}-\mathrm{R})$ through a Schiff base reaction. ${ }^{48,49}$ Based on this approach, one can then obtain direct cross-linking between the $\mathrm{CHI}$ and $\mathrm{ADA}$ chains without using toxic cross-linking agents. ${ }^{50}$ Aston and co-workers have investigated the interaction between $\mathrm{CHI}$ and $\mathrm{ADA}$ using

Received: November 11, 2018

Accepted: January 10, 2019

Published: January 25, 2019 
Scheme 1. Mechanism for the Formation of Schiff Base Bonds between Chitosan (CHI) and Alginate Dialdehyde (ADA) and for Reductive Amination of the Cross-Links

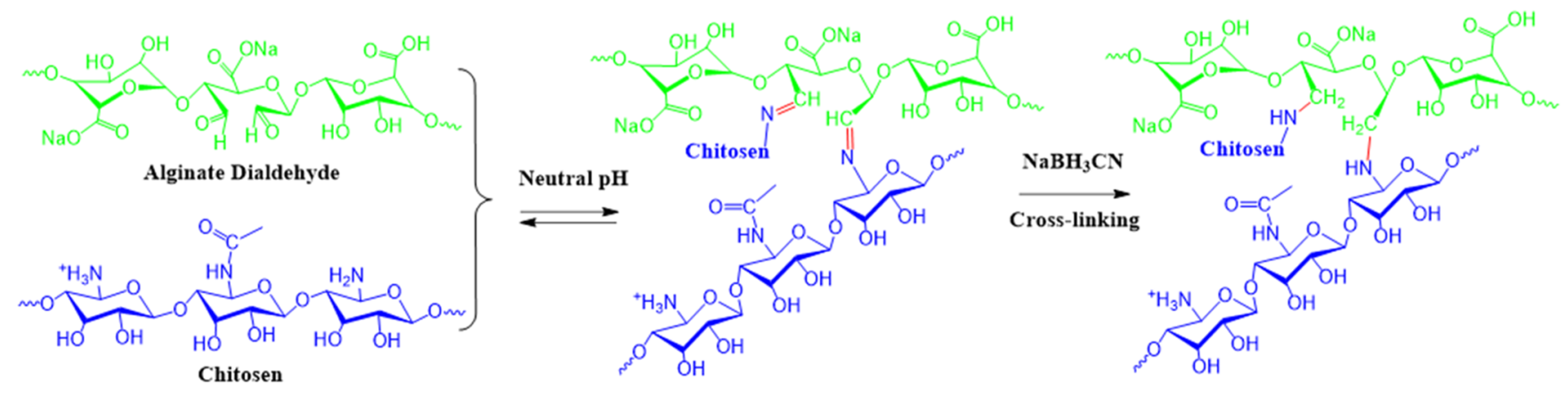

several spectroscopy methods and suggested improved stability because of the formation of the covalent bonds within the film. $^{35}$ In another relevant work, Jia and co-workers have fabricated hollow microcapsules based on $\mathrm{CHI} / \mathrm{ADA}^{51}$ As reported in their work, $\mathrm{CHI} / \mathrm{ALG}$ microcapsules were promptly dissolved in $0.1 \mathrm{M} \mathrm{HCl}$ and $0.1 \mathrm{M} \mathrm{NaOH}$ solutions, whereas $\mathrm{CHI} / \mathrm{ADA}$ microcapsules were stable under both acidic and alkaline conditions for at least $24 \mathrm{~h}$. Wang and coworkers have used $\mathrm{ADA}$ as a natural cross-linker to obtain chitosan/calcium polyphosphate composite scaffolds for meniscus tissue engineering and suggested the formation of a three-dimensional (3D) cross-linked network. ${ }^{52}$ Zhao and coworkers have prepared composite nanofibers of carboxymethyl chitosan cross-linked with ADA. They have also inferred enhanced stability in both acidic (1 M HAc) and alkaline (1 M $\mathrm{NaOH})$ solutions for at least 3 days. ${ }^{53}$ Liang and co-workers have fabricated a hydrogel based on hydroxypropyl chitosan and ADA, which was examined with respect to cytotoxicity, histocompatibility, and degradability in vivo for tissue engineering. ${ }^{54} \mathrm{Mu}$ and co-workers have fabricated $\mathrm{CHI} / \mathrm{ADA}$ microcapsules, which were reportedly stable under acidic and neutral conditions but could disintegrate in strongly alkaline media ( $\mathrm{pH}$ 12). ${ }^{55}$ Accordingly, the intrinsic stability toward $\mathrm{pH}$ changes and natural biocompatibility of CHI/ADA multilayered films make them a potential coating material with applications in drug delivery and tissue engineering.

In this work, we fabricated a self-cross-linked CHI/ADA multilayered film that is both $\mathrm{pH}$ - and salt-responsive. Although the multilayer buildup is still driven by electrostatic attraction, the formation of additional imine bonds can provide enhanced stability. However, the Schiff base is reportedly a dynamic covalent bond meaning that it can dissociate specifically under acidic conditions. ${ }^{56,57}$ For this reason, we have post-modified the assembled film by a reductive amination reaction using sodium cyanoborohydride to transform the reversible imine bonds $(\mathrm{R}-\mathrm{CH}=\mathrm{N}-\mathrm{R})$ into permanent amine bonds $\left(\mathrm{R}-\mathrm{CH}_{2}-\mathrm{NH}-\mathrm{R}\right) \cdot{ }^{58}$ After stabilizing the cross-linked structure, the stimuli-responsive behavior of the multilayered film with respect to changes in $\mathrm{pH}$ and addition of multivalent salts was investigated. In situ QCM-D and spectroscopic ellipsometry measurements were carried out to thoroughly examine the structural properties of the multilayer such as thickness, conformation, water content, and refractive index.

\section{EXPERIMENTAL SECTION}

2.1. Materials. Sodium alginate (NaALG, viscosity $\geq 2000$ $\mathrm{cP}$ for $2 \%$ solution in water at $25^{\circ} \mathrm{C}$ ), chitosan ( $\mathrm{CHI}$, a degree of deacetylation of $75-85 \%$, viscosity $20-300 \mathrm{cP}$ for $1 \%$ solution in acetic acid at $25{ }^{\circ} \mathrm{C}$ ), 3-glycidoxypropyltrimethoxysilane (GPS, $\geq 98 \%)$, sodium hydroxide $(\mathrm{NaOH}, \geq 97 \%)$, hydrochloric acid $(\mathrm{HCl}, 37 \%)$, dibasic sodium phosphate $\left(\mathrm{Na}_{2} \mathrm{HPO}_{3}, \geq 99 \%\right)$, sodium dihydrogen phosphate $\left(\mathrm{NaH}_{2} \mathrm{PO}_{3}, \geq 99 \%\right)$, sodium cyanoborohydride $\left(\mathrm{NaBH}_{3} \mathrm{CN}\right.$, $95 \%)$, sodium metaperiodate $\left(\mathrm{NaIO}_{4}, \geq 99.5 \%\right)$, hydroxylamine hydrochloride $\left(\mathrm{HONH}_{2} \cdot \mathrm{HCl}, 99.99 \%\right)$, sodium chloride $(\mathrm{NaCl}, \geq 99 \%)$, sodium bicarbonate $(\geq 99.7 \%)$, calcium chloride $\left(\mathrm{CaCl}_{2}, \geq 99 \%\right)$, sodium sulfate $\left(\mathrm{Na}_{2} \mathrm{SO}_{4}, \geq 99 \%\right)$, methyl orange reagent (85\%), and ethylene glycol (99.8\%) were all purchased from Sigma-Aldrich. Degassed ultrapure water (Milli-Q Plus 185 system with a $0.2 \mu \mathrm{m}$ Millipak filter) with a resistivity of $18.2 \mathrm{M} \Omega \mathrm{cm}$ and organic content below 5 $\mathrm{ppb}$ was used to prepare all of the buffers and polymer solutions.

Alginate dialdehyde (ADA) was prepared using sodium periodate $\left(\mathrm{NaIO}_{4}\right)$, as previously reported. ${ }^{59-61} \mathrm{~A}$ detailed description of the oxidation procedure and characterization data is provided in Section S1, Supporting Information. ADA stock solution $(1 \% \mathrm{w} / \mathrm{v})$ was prepared in Milli-Q water with no $\mathrm{pH}$ adjustment. CHI was purified by filtration and freezedrying, as reported previously. ${ }^{25,30}$ The obtained powder was then dissolved in $1 \%(\mathrm{v} / \mathrm{v}) \mathrm{HCl}$ solution to obtain a $1 \%(\mathrm{w} / \mathrm{v})$ stock solution. Next, $100 \mathrm{ppm}$ CHI and $200 \mathrm{ppm}$ ADA solutions in $15 \mathrm{mM}$ phosphate-buffered saline (PBS) buffer were prepared by diluting the stock solutions and the $\mathrm{pH}$ of both solutions was adjusted to 6 . For post-reduction of the fabricated film, solutions containing $30 \mathrm{mM} \mathrm{NaBH}_{3} \mathrm{CN}$ in 15 $\mathrm{mM}$ PBS at pH 6 and 9 were also prepared. To investigate the effect of $\mathrm{pH}$, a solution containing $14.1 \mathrm{mM} \mathrm{NaCl}$ and $1 \mathrm{mM}$ $\mathrm{NaHCO}_{3}$ (total ionic strength of $15.1 \mathrm{mM}$ ) was used as the reference buffer. Hereafter, the $\mathrm{pH}$ of this solution was adjusted to 2, 6, and 9 using $\mathrm{HCl}$ or $\mathrm{NaOH}$. For the multivalent salt solutions, $4.7 \mathrm{mM} \mathrm{Na}_{2} \mathrm{SO}_{4}$ and $4.7 \mathrm{mM} \mathrm{CaCl}_{2}$ were each mixed with $1 \mathrm{mM} \mathrm{NaHCO}$ (total ionic strength of $15.1 \mathrm{mM}$ ) and the $\mathrm{pH}$ was adjusted to 2,6 , and 9, respectively.

2.2. Quartz Crystal Microbalance with Dissipation Monitoring (QCM-D). QCM-D (Q-Sense E1, Biolin Scientific, Gothenburg, Sweden) measurements were performed to monitor the LbL buildup and stimuli-responsive behavior of the multilayer. In such an experiment, the frequency $(f)$ of the oscillating crystal inversely correlates with the total mass coupled with the sensor. In addition, QCM-D monitors the oscillation decay after the driving voltage is repeatedly switched on and off, providing the dissipation (damping) factor as a semiquantitative measure of the film "softness". The measured shifts in the oscillation 
Scheme 2. Schematic Illustration of (A) in Situ QCM-D and Spectroscopic Ellipsometry Setup and (B) Optical Models Used To Characterize the Optical Thickness, Refractive Index, and Water Content of the Film

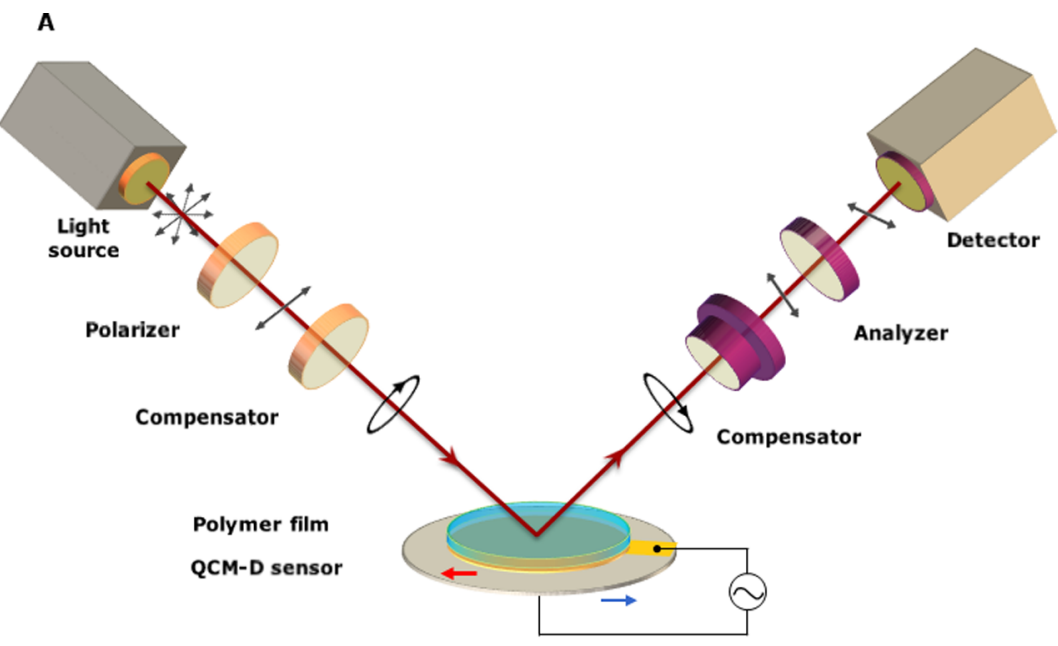

B
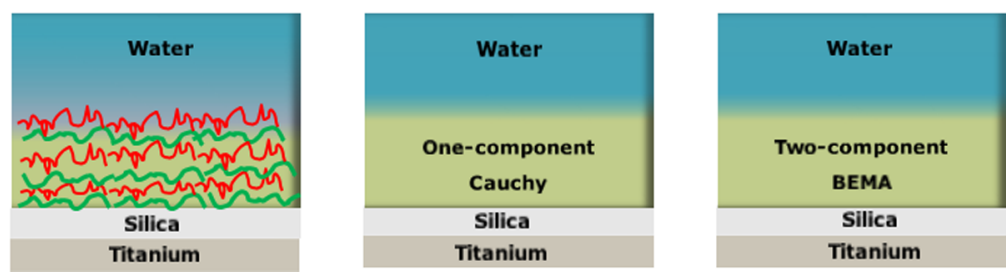

frequency and dissipation for different overtones can be related to the thickness and viscoelastic properties of the polymer film using different modeling approaches. For thin, uniform, and rigid films, the frequency shifts show a linear dependence on the adsorbed mass per unit area according to the Sauerbrey equation $^{62}$

$$
\Delta m_{\text {Sau }}=-C \frac{\Delta f}{n}
$$

where $m_{\text {sau }}$ is the sensed mass according to the Sauerbrey estimation, $C$ is the mass sensitivity constant of the sensor $\left(0.181 \mathrm{mg} \mathrm{m}^{-2} \mathrm{~Hz}^{-1}\right.$ for the crystals with a resonance frequency of $4.95 \mathrm{MHz}$ ), and $n$ is the overtone number. The Sauerbrey equation considers the adsorbed film as a rigid film that perfectly follows the sensor oscillation with no viscous deformation. Hence, the above equation can provide a valid estimation only if the ratio of dissipation and normalized frequency shifts $\left(\left(\Delta D_{n}\right) /\left(-\Delta f_{n} / n\right)\right)$ is smaller than $4 \times 10^{-7}$ $\mathrm{Hz}^{-1}$; otherwise, the adsorbed mass will be underestimated. ${ }^{62}$ In contrast, soft and highly hydrated polymeric films generally cannot be quantified by the Sauerbrey estimation, meaning that the linear relationship between the frequency shift and the adsorbed mass no longer holds. Instead, the so-called effective coupled mass depends on how the oscillatory acoustic wave propagates through the attached film. As a result, additional effects from the coupled water (either bound or unbound) and the viscous drag force will contribute to the frequency shifts. $^{62,63}$ Under this condition, the viscoelastic Voigt modeling can provide a better estimation, where the adhered film is represented by a layer of uniform thickness and density with distinct viscous and elastic components. ${ }^{64,65}$ Accordingly, the frequency and dissipation shifts are related to the properties of the film and medium by

$$
\begin{aligned}
& \frac{\Delta f}{f}=-\frac{d_{\mathrm{f}} \rho_{\mathrm{f}}}{d_{\mathrm{q}} \rho_{\mathrm{q}}}\left(1-\eta_{0} \rho_{0} \times \frac{\left(\eta_{\mathrm{f}} / \rho_{\mathrm{f}}\right) \omega^{2}}{\left(\mu_{\mathrm{f}}^{2}+\omega^{2} \eta_{\mathrm{f}}^{2}\right)}\right) \\
& \Delta D=\frac{d_{\mathrm{f}}}{d_{\mathrm{q}} \rho_{\mathrm{q}}}\left(\eta_{0} \rho_{0} \times \frac{\mu_{\mathrm{f}} \omega}{\mu_{\mathrm{f}}^{2}+\omega^{2} \eta_{\mathrm{f}}^{2}}\right)
\end{aligned}
$$

where $\omega$ is the angular frequency of oscillation, $\eta_{0}$ and $\rho_{0}$ are the viscosity and density of the medium, and $d_{\mathrm{q}}$ and $\rho_{\mathrm{q}}$ are the thickness and density of the quartz crystal resonator. ${ }^{64,65}$ To avoid overparameterization, the medium density, medium viscosity, and film density are estimated and then treated as fixed parameters in the model. Therefore, the thickness $\left(d_{\mathrm{f}}\right)$, viscosity $\left(\eta_{\mathrm{f}}\right)$, and shear modulus $\left(\mu_{\mathrm{f}}\right)$ of the polymeric film are obtained by fitting the Voigt model to the measured shifts in frequency and dissipation for different overtones. The instrument software (Dfind, Biolin Scientific) was herein employed for modeling the data. The density of the film $\left(\rho_{\mathrm{f}}\right)$ was estimated to be $1100 \mathrm{~kg} \mathrm{~m}^{-3}$ (estimation of $\rho_{\mathrm{f}}$ is provided in Section S2, Supporting Information). ${ }^{64,66,67}$ The density and viscosity of water at $25{ }^{\circ} \mathrm{C}$ (provided in the software library) were used for the medium.

2.3. Spectroscopic Ellipsometry. Spectroscopic ellipsometry (M-2000X, J.A. Woollam Co., Inc.) measurements were performed simultaneously with QCM-D, using the QSense Ellipsometry Module (Biolin Scientific). In a typical spectroscopic ellipsometry configuration (Scheme 2), spectroscopic light from a light source passes through a polarizer unit that sets the incident polarization state. ${ }^{68,69}$ The interaction of light with the sample leads to a change in the polarization state of the light, which is described in terms of ellipsometric $\psi$ and $\Delta$. These parameters are related to the thickness and optical properties of the sample according to 


$$
\tan \psi \mathrm{e}^{\mathrm{i} \Delta} \equiv \frac{r_{\mathrm{p}}}{r_{\mathrm{s}}} \equiv \rho\left(\theta_{0}, h_{1}, \ldots, \quad h_{j}, N_{\mathrm{a}}, N_{\mathrm{s}}, N_{1}, \ldots, N_{j}\right)
$$

The subscripts $\mathrm{p}$ and $\mathrm{s}$ refer to parallel and perpendicular directions with respect to the plane of incidence, and $r_{\mathrm{p}}$ and $r_{\mathrm{s}}$ represent the reflection coefficients. $\psi$ represents the angle determined from the amplitude ratio between $\mathrm{p}$ - and $\mathrm{s}$ polarizations, whereas $\Delta$ refers to the phase difference between the two components. The complex reflectance ratio $(\rho)$ is a function of the optical structure of the sample and includes information about its physical properties. The polarization state of the reflected light accordingly depends on the angle of incidence $\left(\theta_{0}\right)$, the thicknesses $\left(h_{j}\right)$ of the layers, the complex refractive indices $\left(N_{j}=n_{j}+i k_{j}\right)$ of the layers, the ambient $\left(N_{\mathrm{a}}\right)$, and the substrate $\left(N_{s}\right)$. Knowing the nominal structure of the sample and using appropriate optical models, one can predict $\psi$ and $\Delta$ from the Fresnel's equation, whereafter the best match between the modeled and experimentally determined angles will be found through regression.

Herein, the ellipsometric $\psi$ and $\Delta$ were obtained over a wavelength range between 250 and $1000 \mathrm{~nm}$ and at a $70^{\circ}$ angle of incidence. The instrument software (CompleteEASE, J.A. Woollam) was employed to fit the optical models to the ellipsometric data. The optical model used herein is composed of three layers (Scheme 2) representing a uniform hydrated polymer film, a silica coating, and a thick optically opaque titanium substrate. $^{70,71}$ The bare sensor surface was modeled as a "pseudosubstrate" from the ellipsometric data obtained for the bare sensor in the buffer; then, the fitted parameters were fixed in the model (detailed description of modeling is available in Section S3, Supporting Information). For the medium, the optical data of pure water at $25{ }^{\circ} \mathrm{C}$ from the software library was used. Considering that the ionic strength of all of the used buffer solutions was around $15 \mathrm{mM}$, the changes in the refractive index from water can be considered to be minor. ${ }^{72}$ The CHI/ADA multilayered film was considered to be a transparent and homogeneous single layer with no adsorption; then, its refractive index was described by the Cauchy dispersion ${ }^{67}$

$$
n_{\mathrm{f}}=A_{\mathrm{f}}+B_{\mathrm{f}} /(\lambda)^{2}+C_{\mathrm{f}} /(\lambda)^{4}
$$

In this equation, $C_{\mathrm{f}}$ was fixed to 0 to avoid correlation between the fitting parameters. The hydrated multilayered film was first considered as a single-component Cauchy layer, where its thickness and effective dispersion coefficients $\left(A_{\text {eff }}, B_{\text {eff }}\right)$ were estimated from fitting. Alternatively, the hydrated film was modeled as a two-component layer composed of a dry polymer and water; then, the layer thickness and volume fraction of water were estimated from fitting. The dry polymeric component was considered to be homogeneous in optical behavior, and estimated values of $A_{\text {polymer }}=1.51$ and $B_{\text {polymer }}=$ 0.005 were used for the mixture of $\mathrm{CHI}$ and ADA. ${ }^{73}{ }^{7} 73^{3}$ The volume fraction of water $\left(\varphi_{\mathrm{w}}\right)$ was related to the refractive indices of the hydrated layer $\left(n_{\text {mix }}\right)$, dry polymer $\left(n_{\text {polymer }}\right)$, and water $\left(n_{\text {water }}\right)$ using the Bruggeman effective medium approximation (BEMA) given as

$$
\varphi_{\mathrm{w}} \frac{n_{\mathrm{w}}^{2}-n_{\text {mix }}^{2}}{n_{\mathrm{w}}^{2}+2 n_{\text {mix }}^{2}}+\left(1-\varphi_{\mathrm{w}}\right) \frac{n_{\text {polymer }}^{2}-n_{\text {mix }}^{2}}{n_{\text {polymer }}^{\mathrm{w}}+2 n_{\text {mix }}^{2}}=0
$$

Several modeling options such as surface roughness, thickness nonuniformity, anisotropicity, and grading were checked; however, none of which significantly improved the fitting quality and were found to impose cross-correlation between the fitting parameters. The quality of the fitting was evaluated according to the mean-squared error value (MSE < 10), the uniqueness of the fitted parameters, and a weak correlation between the fitting parameters (the optimization of the optical models is discussed in Section S4, Supporting Information).

2.4. Layer-by-Layer (LbL) Assembly. Silica-sputtered quartz sensors (QSX 335, Biolin Scientific) recommended for in situ QCM-D and ellipsometry measurements were employed herein. First, the sensor was repeatedly washed with acetone and absolute ethanol, then rinsed with copious amounts of Milli-Q water, and finally dried by compressed air. To remove possible organic contaminants, the sensor was hereafter plasma-treated (PDC-32G plasma cleaner, Harrick Plasma) using medium power under a constant water pressure of $500 \mathrm{mT}$ orr for $5 \mathrm{~min}$. To graft CHI to the silica surface, the silica surface was coated with GPS. ${ }^{76}$ To do so, the sensor was immersed in $18 \% \mathrm{v} / \mathrm{v}$ GPS/acetone solution for $22 \mathrm{~h}$, followed by rinsing with acetone several times, and dried for $40 \mathrm{~min}$ at $100{ }^{\circ} \mathrm{C}$. The first chitosan layer was then grafted to the sensor using the amino-oxirane addition reaction, ${ }^{77,78}$ by dipping the GPS-coated sensor in a $1 \%(\mathrm{w} / \mathrm{v})$ chitosan solution with $\mathrm{pH} 6$ for $40 \mathrm{~min}$, followed by rinsing with water. The sensor with a grafted CHI layer was then mounted in the in situ QCM-D/ ellipsometry module, and the measurement was started under a $150 \mu \mathrm{L} \mathrm{min}^{-1}$ flow rate of $15 \mathrm{mM}$ PBS buffer with $\mathrm{pH} 6$ at 25 ${ }^{\circ} \mathrm{C}$. After obtaining a stable baseline for all of the harmonics (3rd-13th overtones), the following LbL deposition procedure was conducted. The ADA solution was pumped into the chamber for $40 \mathrm{~min}$, followed by $20 \mathrm{~min}$ rinsing with PBS buffer. Using the same procedure, $\mathrm{CHI}$ and $\mathrm{ADA}$ layers were sequentially deposited onto the sensor to obtain an overall layer number of 15 (including the pregrafted CHI layer). Deposition of the layers was performed at $\mathrm{pH} \mathrm{6,} \mathrm{which} \mathrm{is}$ relatively close to the expected $\mathrm{p} K_{\mathrm{a}}$ value for $\mathrm{CHI}\left(\mathrm{p} K_{\mathrm{a}}\right.$ is about $6.3-6.5){ }^{10,11}$ This $\mathrm{pH}$ value was chosen as a compromise between on one hand having enough $-\mathrm{NH}_{3}{ }^{+}$groups to ensure solubility of $\mathrm{CHI}$ and on the other hand having enough $-\mathrm{NH}_{2}$ groups to form Schiff base cross-links between $\mathrm{CHI}$ and ADA. ${ }^{79}$ The fabricated multilayered film was then post-treated using $\mathrm{NaBH}_{3} \mathrm{CN}$ solution to transform the dynamic imine bond into a permanent amine bond. ${ }^{49,58}$ To do so, the $\mathrm{NaBH}_{3} \mathrm{CN}$ solution with $\mathrm{pH} 6$ was first pumped into the chamber for $30 \mathrm{~min}$, followed by rinsing and then a $1 \mathrm{~h}$ treatment by $\mathrm{NaBH}_{3} \mathrm{CN}$ solution at $\mathrm{pH}$ 9. After cross-linking, the chamber was reloaded with $15 \mathrm{mM}$ PBS solution at $\mathrm{pH} 6$.

The effect of $\mathrm{pH}$ and multivalent ions on the multilayer properties was later investigated. The baseline was obtained in the reference buffer $\left(14.1 \mathrm{mM} \mathrm{NaCl}\right.$ and $1 \mathrm{mM} \mathrm{NaHCO}_{3}$ at $\mathrm{pH} 6$ ). Hereafter, the $\mathrm{pH}$ was repeatedly changed (three times) between 6 and 2 and then between 6 and 9. An equilibration time of $40 \mathrm{~min}$ was given in between each $\mathrm{pH}$ change. To investigate the effect of multivalent ions, the solutions of $\mathrm{NaCl}$, $\mathrm{Na}_{2} \mathrm{SO}_{4}$, and $\mathrm{CaCl}_{2}$ of different $\mathrm{pH}$ values were loaded. Throughout the experiment, the ellipsometric $\psi$ and $\Delta$ values were measured at the end of each rinsing step.

\section{RESULTS AND DISCUSSION}

3.1. LBL Assembly. Figure 1A illustrates the QCM-D data in terms of the measured shifts in the oscillation frequency and the dissipation factor during the multilayer growth. The oscillation frequency $(f)$ is inversely related to the effective 

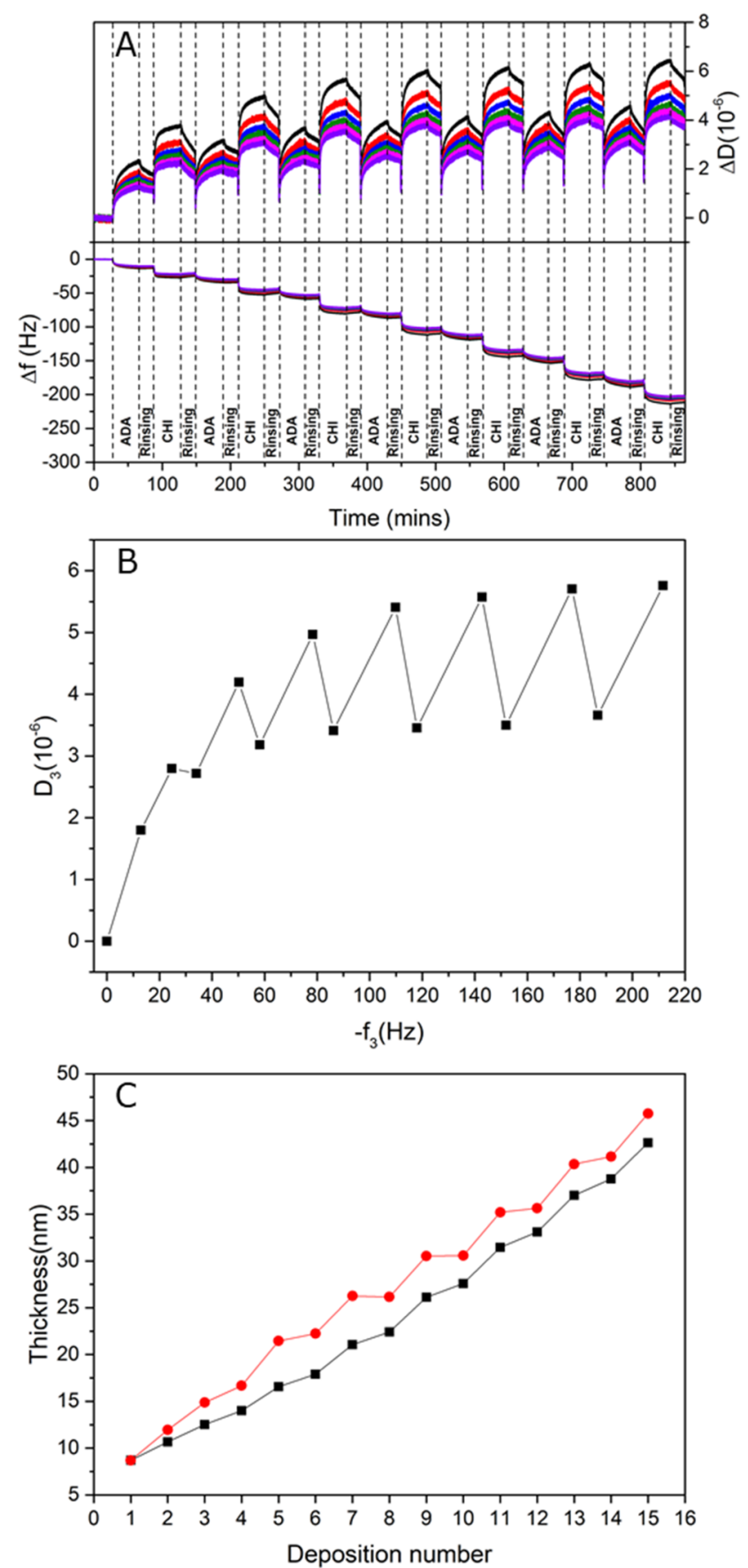

Figure 1. QCM-D data for LbL buildup in $15 \mathrm{mM}$ PBS buffer at $\mathrm{pH}$ 6: (A) Frequency and dissipation changes (black: $f_{3}$ and $D_{3}$; red $f_{5}$ and $D_{5}$; blue: $f_{7}$ and $D_{7}$; olive: $f_{9}$ and $D_{9}$; magenta: $f_{11}$ and $D_{11}$; violet: $f_{13}$ and $D_{13}$ ) as a function of time. (B) Dissipation vs frequency shifts for the third overtone upon each layer deposition. (C) Film Thickness from the Sauerbrey (black square) and Voigt (red circle) models as a function of deposition number.

mass coupled with the sensor, which in the present case includes the adsorbed polymer chains and the water content associated with the multilayer. The dissipation factor (D) provides semiquantitative information about the structural properties of the polymeric film, i.e., a soft and swollen film is characterized by a large dissipation factor, whereas a rigid and compact film is quantified by a relatively small damping factor.
In Figure 1A, a monotonic decrement in the oscillation frequency is observed upon each deposition step, indicating adsorption of the polymers to the sensor and effective LbL assembly. On the other hand, the dissipation factor demonstrates an overall increment but with a nonmonotonic trend, which can suggest conformational restructuring during the LbL assembly. The growth mechanism and structural evolutions can be better examined according to Figure 1B, where the dissipation shifts are plotted against the frequency shifts for each deposited layer. Deposition of the first bilayer $(\mathrm{ADA}+\mathrm{CHI})$ is accompanied with a relatively large dissipation shift of around 2.8 and a frequency shift of around $-30 \mathrm{~Hz}$, which together indicate a rather swollen and hydrated structure in the beginning. Beyond the first bilayer (where the surface decoupling effect is likely), a zigzag trend is however demonstrated. Accordingly, deposition of CHI, in general, is accompanied by a frequency shift of around $-20 \mathrm{~Hz}$ and a dissipation shift of around 2. In contrast, deposition of ADA is characterized by a relatively smaller frequency shift of around $-10 \mathrm{~Hz}$ and a decrement of around 2 in dissipation. These opposite effects can be reasoned on the basis of the charge density and conformation of the adsorbed layers, which promote restructuring of the film during growth. ${ }^{17,22} \mathrm{CHI}$ reportedly demonstrates a $\mathrm{p} K_{\mathrm{a}}$ in the range of $6.3-6.5\left(\mathrm{p} K_{\mathrm{a}}\right.$ of amine is 6.3$),{ }^{10,11}$ meaning that $\mathrm{CHI}$ chains possess a relatively low charge density and swollen coil conformation at $\mathrm{pH} 6$, at which the multilayered film is fabricated. ADA with a $\mathrm{p} K_{\mathrm{a}}$ of 3.4-3.7 is however highly charged and stretched under this $\mathrm{pH}$ condition. ${ }^{35}$ As a result, when $\mathrm{CHI}$ is adsorbed as the topmost layer, one can expect a dangling and swollen interfacial layer high in loops and tails, which is in agreement with the large increment in dissipation upon CHI deposition. Such a swollen top layer is also accompanied by a relatively large water content, which can be another reason for the marked gain in dissipation. These two inter-related effects could be responsible for the rather larger frequency shift. On the one hand, the relatively large hydrodynamic water content can strongly contribute to the effective sensed mass, causing viscous drag forces. On the other hand, $\mathrm{CHI}$ is less charged compared with $\mathrm{ADA}$ at the deposition conditions, partly due to the lower density of dissociable groups (which is determined by the degree of deacetylation) and partly due to the proximity to the $\mathrm{pK}_{\mathrm{a}}$ value of CHI. Thus, a relatively larger amount of CHI monomers should be adsorbed to compensate the $\mathrm{ADA}$ charge. $^{17,79}$

On the contrary, deposition of the highly charged and elongated $\mathrm{ADA}$ chains can suppress the dangling $\mathrm{CHI}$ loops and tails, which can give rise to a more compact and less hydrated $\mathrm{CHI}$ layer beneath. It should also be considered that the adsorbed ADA can form covalent cross-links with the CHI layer beneath, which can make the interfacial top layer more rigid. Therefore, two cross-effects are plausible upon deposition of ADA. On the one hand, a certain amount of new polymer (effective mass) is added to the multilayer and then the sensor, which corresponds to an expected positive dissipation shift and a negative frequency shift. On the other hand, the swollen CHI layer beneath consequently transforms into a relatively compact and dehydrated sublayer, which is characterized by a decrement in dissipation (collapse) and increment in frequency (water loss). The counterbalance of these two effects could justify the negative dissipation shift and relatively small frequency change upon $\mathrm{ADA}$ deposition. A closer examination of the results also reveals that after the first 
two bilayers the dissipation value of the film roughly fluctuates between 3.5 (when ADA is the outer layer) and 5.5 (when $\mathrm{CHI}$ is the outer layer). This observation confirms that the structure and water content of the multilayer are mostly governed by the topmost layer, whereas the sublayers are found in a compact state and probably lose water following the multilayer growth.

The Sauerbrey and viscoelastic Voigt models were fitted to the QCM-D data to estimate the thickness of the film (Figure 1C). Regardless of the model used, it can be inferred that the $\mathrm{LbL}$ assembly follows a linear growth mechanism, which is in accordance with the previously reported CHI/ALG systems. $^{17,18,21-25,30-32,39,41}$ The thickness of the deposited film is estimated to be around 46 and $43 \mathrm{~nm}$ from the Voigt and Saurebrey models, respectively. Even though the Sauerbrey model slightly underestimates the film thickness, the two models are found to be in fair agreement, which is a further indication of rather low water content and compacted structure of the polymeric film. As another important observation, the increment in thickness per CHI layer is found to be considerably larger than that per ADA layer, which can suggest that $\mathrm{CHI}$ adsorbs in a more swollen and hydrated state. To further examine the structural characteristics of the multilayer, spectroscopic ellipsometry measurements were simultaneously conducted.

Figure 2 illustrates the spectroscopic ellipsometric data in terms of the amplitude ratio $(\psi)$ and phase shift $(\Delta)$ after each

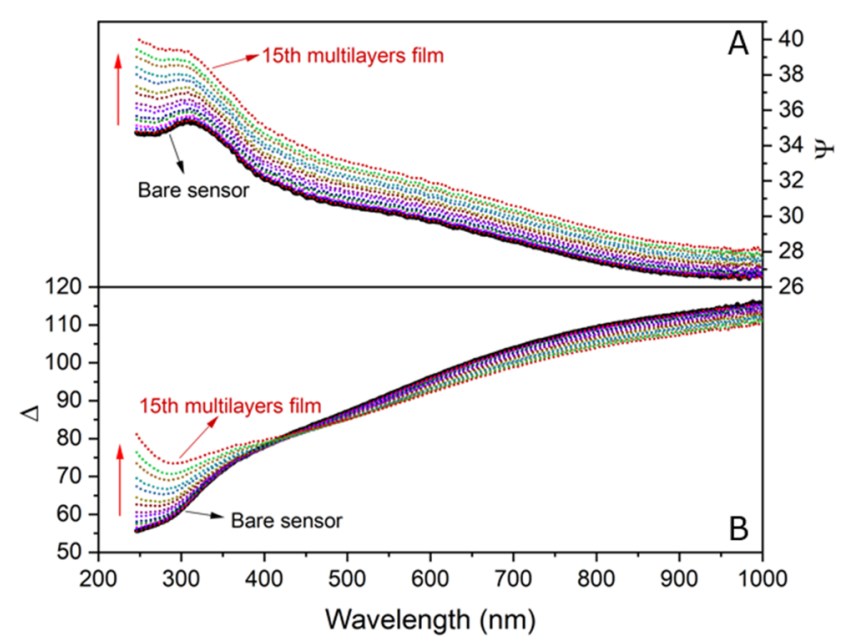

Figure 2. Ellipsometry data for LbL buildup in $15 \mathrm{mM}$ PBS buffer at pH 6. (A) $\Psi$ and (B) $\Delta$ spectra for the bare and polymer-coated sensors (the black solid curve shows the data for bare sensor, and the arrows indicate the increasing number of deposited layers).

deposition step. With respect to the bare sensor (the black solid curve), an oscillation peak in the UV range is demonstrated in both $\psi$ and $\Delta$ spectra, which can be attributed to the optical interference from the transparent silica coating on the sensor. The LbL deposition of the polymeric film on the sensor is accompanied by marked changes in both $\psi$ and $\Delta$ spectra. With respect to $\psi$ (panel A), a monotonic increment in the amplitude (upward shift) is demonstrated at all of the wavelengths, whereas a gradual red shift in the spectra is found upon deposition of each layer. The red shift effect can be more vividly inferred from the tail of a second peak gradually evolving at low wave numbers. Both the observations suggest monotonic growth of a thin transparent film on the sensor that can produce optical interference, spectral oscillation, and then a gain in $\psi$. A similar conclusion can be obtained from $\Delta$ spectra (panel B), where a red shift in the spectra is shown while a clear spectral oscillation evolves upon polymer deposition. Although some general information can be deduced from the raw data, it is somewhat challenging to obtain detailed physical information on the deposited layer from the raw data. Thus, the ellipsometry data were modeled to assess the film properties more quantitatively (Table 1).

Both Cauchy and BEMA models suggest a thickness of around $16 \mathrm{~nm}$ for the multilayered film, which is found to be relatively smaller than the thickness estimated from QCM-D modeling (around $45 \mathrm{~nm}$ ). This difference between the optical and acoustic thicknesses might be attributed to the sporadic presence of self-assembled structures (with a height of around 10-100 nm), which can be detected from the AFM images of the sample (Section S5, Supporting Information). Such structures can produce additional contributions from viscous drag force and coupling of hydrodynamic hydration to the frequency and dissipation shifts, which could provide an overestimated film thickness. ${ }^{64,77,79-82}$ On the other hand, the optical thickness is determined on the basis of the nominal difference (contrast) between the refractive indices of water and the hydrated film. Accordingly, whereas QCM-D is more sensitive to the topmost polymer chains and aggregated structures, ellipsometry in principle sees the dense optically different regions of the film. ${ }^{83-85}$ It should also be noted that for thin polymeric films one can always expect a certain uncertainty when fitting for thickness and optical constants simultaneously. ${ }^{86,87}$ In the BEMA model, the multilayered film is considered as a uniform mixture of dry polymer and water, which then can provide an estimation of the water content (volume fraction) in the film. The water content for the whole film was estimated to be around $3.5(\mathrm{v} / \mathrm{v} \%)$, suggesting a dense and low hydrated structure in agreement with the QCM-D data. The low water content obtained herein is probably due to the correlation between the thickness and optical constants of the film, which has been previously observed for optical modeling of thin polymeric films (see Section S4, Supporting information).

3.2. Stabilization of the Cross-Links. As discussed above, the aldehyde groups on $\mathrm{ADA}$ form covalent imine bonds $(-\mathrm{CH}=\mathrm{N}-)$ with the primary amine groups on $\mathrm{CHI}$ through the Schiff base reaction. The Schiff base bonding is reportedly a dynamic covalent reaction, meaning that the reaction is reversible and all of the constituents are in

Table 1. Structural Characteristics of the Multilayered Film Obtained from QCM-D and Spectroscopic Ellipsometry in 15 mM PBS at $\mathrm{pH} 6^{a}$

\begin{tabular}{|c|c|c|c|c|c|c|}
\hline $\begin{array}{l}\text { thickness from } \\
\text { Sauerbrey (nm) }\end{array}$ & $\begin{array}{l}\text { thickness from } \\
\text { Voigt (nm) }\end{array}$ & $\begin{array}{l}\text { thickness from } \\
\text { Cauchy (nm) }\end{array}$ & $\begin{array}{l}\text { thickness from } \\
\text { BEMA (nm) }\end{array}$ & $\begin{array}{l}\text { water content } \\
\quad(\mathrm{v} / \mathrm{v} \%)\end{array}$ & $\begin{array}{l}\text { refractive index from } \\
\text { Cauchy }\end{array}$ & $\begin{array}{l}\text { refractive index from } \\
\text { BEMA }\end{array}$ \\
\hline 43 & 46 & $16.0 \pm 0.3$ & $16.1 \pm 0.3$ & $3.5 \pm 1.7$ & 1.522 & 1.516 \\
\hline
\end{tabular}

${ }^{a}$ The refractive indices at $\lambda=632.3 \mathrm{~nm}$ are shown. 
equilibrium. ${ }^{88-90}$ Accordingly, it has been affirmed that the reactivity of Schiff base is notably affected by the $\mathrm{pH}$ of the solution, i.e., higher acidity (typically below $\mathrm{pH} 3$ ) destroys Schiff base, whereas increasing $\mathrm{pH}$ shifts the equilibrium toward Schiff base formation. ${ }^{49,88,91,92}$ To eliminate $\mathrm{pH}$ sensitivity of the covalent bonds and obtain a permanently cross-linked CHI/ADA film, the Schiff base double bond (R$\mathrm{CH}=\mathrm{N}-\mathrm{R}$ ) was herein reduced to a stable single bond ( $\mathrm{R}-$ $\mathrm{CH}_{2}-\mathrm{NH}-\mathrm{R}$ ) using sodium cyanoborohydride as a gentle reducing agent. Cyanoborohydride is known to have a good chemical selectivity, ${ }^{93,94}$ meaning that the unreacted aldehyde group will not be catalyzed to alcohol under neutral and basic conditions. ${ }^{58,95}$ The reduction reaction was conducted in two steps to ensure further stabilization of the structure. First, the reaction was conducted at $\mathrm{pH} 6$ to stabilize the Schiff base bonds formed already during LbL assembly. Afterward, the reduction was performed at $\mathrm{pH} 9$ to favor the formation of more Schiff base bonds that can be converted into permanent cross-links (see Section S6, Supporting Information, for comparison between the stability of multilayered films with and without the postmodification reaction).

Figure 3A presents the shifts in QCM-D frequency and dissipation resulting from cross-linking the film. The two-step cross-linking procedure accordingly produces a minor frequency shift but a relatively large dissipation shift of around
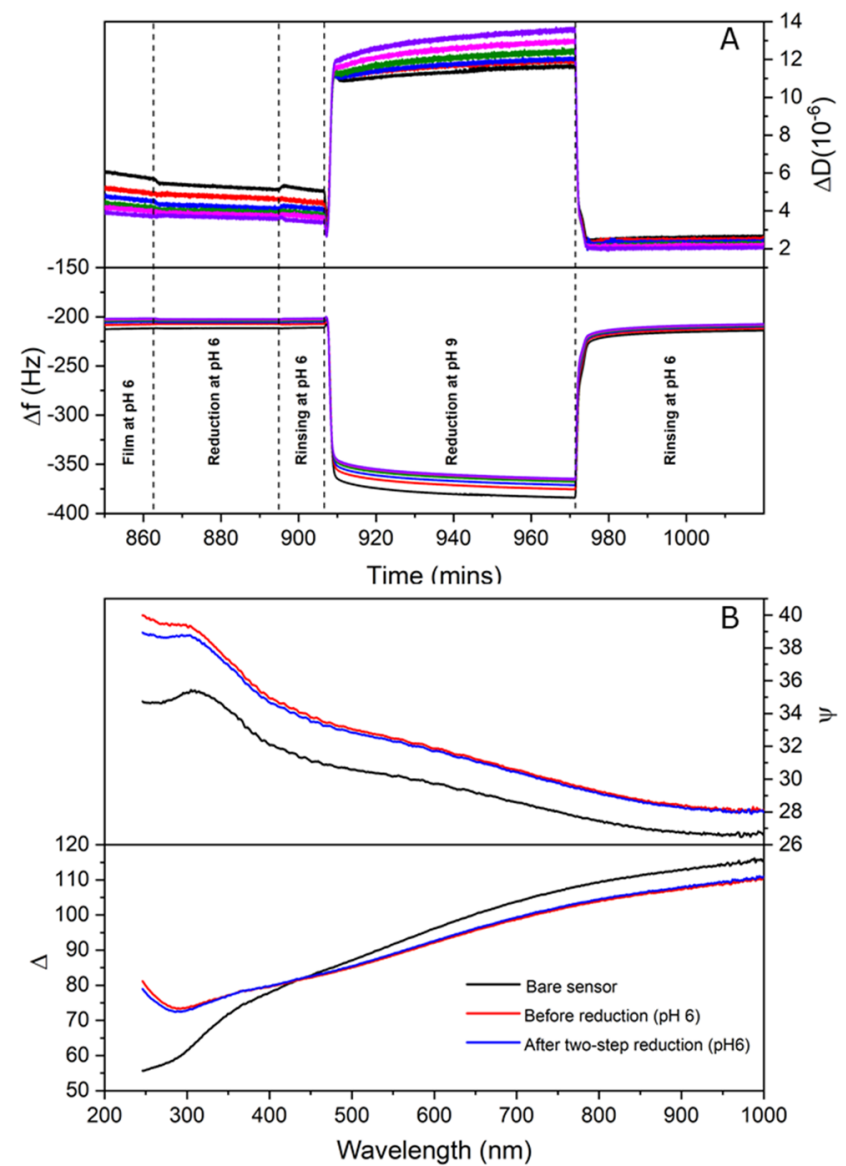

Figure 3. Two-step reduction of the Schiff base bonds in the multilayered film conducted at $\mathrm{pH} 6$ and 9. (A) QCM-D frequency and dissipation changes (black: $f_{3}$ and $D_{3}$; red $f_{5}$ and $D_{5}$; blue: $f_{7}$ and $D_{7}$; olive: $f_{9}$ and $D_{9}$; magenta: $f_{11}$ and $D_{11}$; and violet: $f_{13}$ and $\left.D_{13}\right)$ and (B) ellipsometric $\psi$ and $\Delta$ spectra before and after the process.
-2.5 for the third overtone. The rather large decrement in the dissipation suggests that the multilayer becomes more rigid, which can originate from either water loss or formation of fixed cross-link bonds within the film that can effectively hinder the conformational mobility of the polymer chains. The oscillation frequency, however, remains almost unchanged, which could indicate two counterbalancing effects taking place within the layer.

Figure 3B exhibits the evolution of $\psi$ and $\Delta$ spectra upon cross-linking the film. It is demonstrated that the spectral oscillation in $\psi$ attenuates, whereas the position of the oscillation peak seems almost unchanged. The former observation can imply an increment in the water content of the multilayer, which can then dampen the spectral oscillation because of polymer dilution and then result in less optical contrast with the aqueous medium. The latter observation, however, can be reasoned on the basis of the opposing effects of changes in the thickness and the refractive index on the spectral oscillation position. Accordingly, an increment (decrement) in either the thickness or the refractive index of the film leads to a red shift (blue shift) in the $\psi$ spectra. Since we have already argued that the water content in the layer has increased (drop in the refractive index and then a blue shift effect), the unchanged position of the spectral oscillation can be attributed to a simultaneous increment in the thickness. Such an increment in thickness could also be inferred from the slight amplification of the spectral oscillation in $\Delta$. To further validate these interpretations, the Cauchy and BEMA models were fitted to the raw data. Both models affirm that crosslinking of the multilayered film is accompanied with an increment in thickness from 16 to $19 \mathrm{~nm}$. In addition, a drop in the refractive index at all wavelengths is presented and the water content is found to increase roughly from 3.5 to 27 . Knowing that the layer swells upon cross-linking, one can then speculate that the decrement in the QCM-D dissipation is due to the formation of a 3D permanent cross-linked network in the film. On the other hand, the unchanged frequency data might be due to opposite effects, i.e., the layer swells (larger effective mass) while simultaneously becomes rigid (smaller hydrodynamic contribution). The swelling of the multilayer induced by cross-linking could originate from a charge imbalance condition, resulting from consumption of some amine groups because of the Schiff base formation at $\mathrm{pH}$ 9. It can also be a result of conformational hysteresis induced by changing the $\mathrm{pH}$ to 9 and back to 6 .

3.3. Stimuli-Responsive Behavior: pH Effect. The effect of changing $\mathrm{pH}$ on the thickness and structural characteristics of the cross-linked multilayered film was monitored by QCMD (Figure 4A) and spectroscopic ellipsometry (Figure 4B). As a general observation, the consecutive $\mathrm{pH}$ cycles confirm effective cross-linking that prevents the disintegration of the multilayer. It is worth mentioning that a structural hysteresis is found specifically after the first $\mathrm{pH}$ cycle $(6 \rightarrow 2 \rightarrow 6)$, which could originate from conformational restructuring within the multilayer that can also cause irreversible ionization of amine and carboxyl groups. ${ }^{79}$

Regarding the $\mathrm{pH}$-responsive behavior, changing the condition to acidic $\mathrm{pH}(6 \rightarrow 2)$ is accompanied by a decline in the frequency and a significant gain in the dissipation, which both refer to swelling/rehydration of the multilayer. This can be seen more clearly from the ellipsometry modeling data that show a pronounced growth in thickness from 18 to $34 \mathrm{~nm}$, a drop in the refractive index, and an increment in the water 

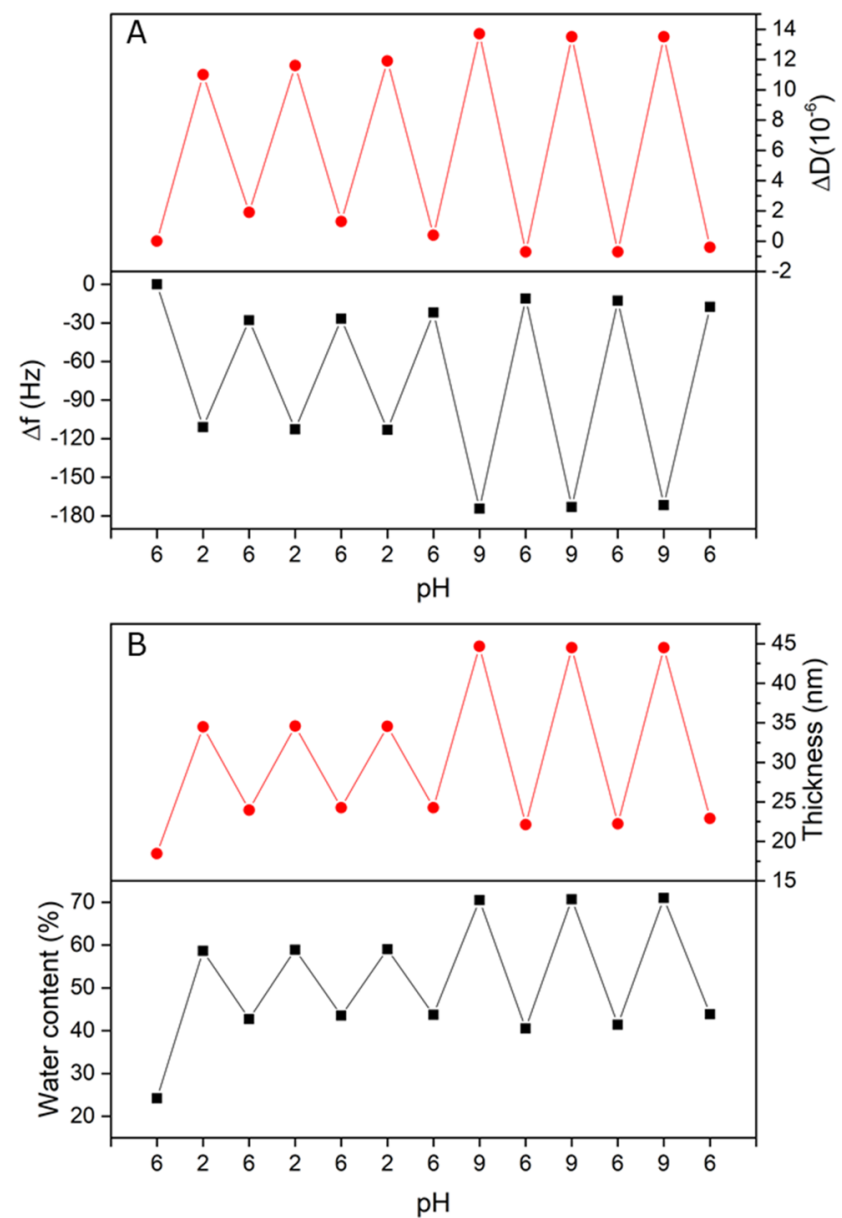

Figure 4. Effect of $\mathrm{pH}$ on the structural properties of the cross-linked CHI/ADA film: (A) QCM-D frequency (black squares) and dissipation change (red circles) and (B) optical thickness (red circles) and water content (black squares) obtained from the BEMA model.

content to $59 \%$. The protonation of amine groups at low $\mathrm{pH}$ values alters the charge balance in the film (net charge of the film becomes more positive), which gives rise to an osmotic swelling of the film. The swelling capacity of the film is governed by the balance between the osmotic pressure of solution and retractive force that originates from the entropic penalty of elastic stretching of the polymer chains between the cross-linking points. ${ }^{96,97}$ Changing the $\mathrm{pH}$ to alkaline condition was similarly followed by a conformational swelling, however, in a more pronounced manner. Accordingly, a dissipation shift of around 14 and a decrement in the frequency of around $170 \mathrm{~Hz}$ were detected. Furthermore, the optical thickness increased to around $45 \mathrm{~nm}$ and the multilayer water content reached up to $71 \%$. The swelling of the film herein can be attributed to the deprotonation of carboxylic acid groups on $\mathrm{ADA}$ that can induce a negative charge in the polymeric film. Finally, it should be noted that while the driving force for swelling at both $\mathrm{pH}$ values 2 and 9 is the osmotic pressure effect, the swelling is limited by the layer conformation, position of cross-links, and length of chain segments between cross-links. Thus, even for a complete charge reversal between acidic and alkaline conditions, the degree of swelling might be different because of the different location and distribution of charged groups.
3.4. Stimuli-Responsive Behavior: Effect of Multivalent Ions. Salts can have specific interactions with polyelectrolytes in terms of ion-specific binding of the counterions to the charged moieties on the polymer backbone, which can induce physical cross-links. ${ }^{10,98-100}$ We have herein compared the effects of calcium chloride $\left(\mathrm{CaCl}_{2}\right)$ and sodium sulfate $\left(\mathrm{NaSO}_{4}\right)$ at three different $\mathrm{pH}$ values, which are depicted in Figure 5. At $\mathrm{pH} \mathrm{6,} \mathrm{where} \mathrm{the} \mathrm{layer} \mathrm{is} \mathrm{in} \mathrm{the}$

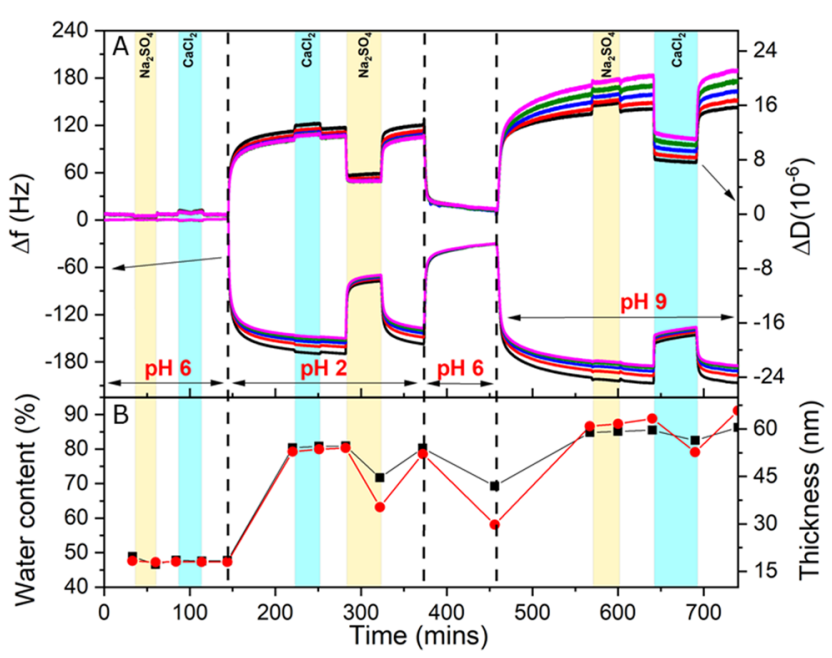

Figure 5. Effect of salts on the structural properties of the cross-linked CHI/ADA film: (A) QCM-D frequency and dissipation change for five overtones (black: $f_{3}$ and $D_{3}$; red $f_{5}$ and $D_{5}$; blue: $f_{7}$ and $D_{7}$; olive: $f_{9}$ and $D_{9}$; and magenta: $f_{11}$ and $D_{11}$ ). (B) Changes in optical thickness (red circles) and water content (black squares) obtained from the BEMA model as a function of time. The yellow and blue highlighted areas represent the $\mathrm{Na}_{2} \mathrm{SO}_{4}$ and $\mathrm{CaCl}_{2}$ response processes, respectively.

proximity of charge neutrality condition, no significant changes in the QCM-D frequency and dissipation or in the ellipsometric thickness and refractive index were detected when switching the salt either from $\mathrm{NaCl}$ to $\mathrm{Na}_{2} \mathrm{SO}_{4}$ or from $\mathrm{NaCl}$ to $\mathrm{CaCl}_{2}$. Although the layer at $\mathrm{pH} 6$ has both negative and positive charges at which $\mathrm{Ca}^{2+}$ and $\mathrm{SO}_{4}{ }^{2-}$ ions could potentially bind to, the layer contains no counterions at this $\mathrm{pH}$ value that could be replaced. As a result, binding of $\mathrm{Ca}^{2+}$ and $\mathrm{SO}_{4}{ }^{2-}$ ions would be entropically costly and unfavorable.

At $\mathrm{pH} 2$, the addition of $\mathrm{NaSO}_{4}$ is accompanied by a notable drop in dissipation and increment in the frequency, both indicating a conformational collapse. In the same line, the ellipsometric thickness is decreased from 54 to $35 \mathrm{~nm}$ and the water content dropped from 81 to $72 \%$. At such acidic conditions, the $\mathrm{CHI}$ chains are positively charged, whereas the ADA chains are mostly uncharged. This overall net positive charge within the film is balanced by $\mathrm{Cl}^{-}$counterions. Accordingly, the observed layer collapse can be explained on the basis of entropic substitution of $\mathrm{Cl}^{-}$with $\mathrm{SO}_{4}{ }^{2-}$ as counterions, which will lead to a drop in the osmotic pressure and thus layer shrinkage. In addition, physical cross-linking, in terms of ion bridges, can also lead to a more rigid network that can also produce a decrement in dissipation. Along the same line, one can argue why the addition of $\mathrm{CaCl}_{2}$ at $\mathrm{pH} 2$ exhibits no significant impact on any of the measured parameters since the layer contains no cationic counterions that can be replaced by $\mathrm{Ca}^{2+}$. On the contrary, at $\mathrm{pH} 9$, where the layer was inferred to be negatively charged and contain $\mathrm{Na}^{+}$as counterions, the 
addition of $\mathrm{CaCl}_{2}$ has resulted in the conformational collapse and dehydration because of binding of $\mathrm{Ca}^{2+}$ ions to the deprotonated carboxyl groups on ADA. For a similar reason, $\mathrm{Na}_{2} \mathrm{SO}_{4}$ is shown to have a limited influence on the layer structure. Accordingly, the multilayered film is, in general, demonstrated to be responsive to the addition of divalent counterions. A qualitatively similar behavior is expected if divalent ions other than $\mathrm{Ca}^{2+}$ and $\mathrm{SO}_{4}{ }^{2-}$ were used; however, one can expect some specific ion effects with respect to the formation of ion bridges and the exact magnitude of the film collapse might thus show ion specificity.

\section{SUMMARY AND CONCLUSIONS}

We have shown that the Schiff base reaction between amine and aldehyde groups can be served as an alternative approach to fabricate cross-linked CHI/ALG films instead of using common cross-linking agents such as glutaraldehyde. In addition, poststabilization of the cross-links in the film using sodium cyanoborohydride allows one to obtain stable covalent cross-links that eliminate $\mathrm{pH}$ sensitivity of Schiff base bonds and then enhance the stability of the film under both acidic and alkaline conditions. Finally, the cross-linked multilayered film is found to be responsive to changes in $\mathrm{pH}$ and addition of salts, showing notable variations in structural properties such as thickness and water content.

\section{ASSOCIATED CONTENT}

\section{S Supporting Information}

The Supporting Information is available free of charge on the ACS Publications website at DOI: 10.1021/acsomega.8b03145.

Detailed synthesis procedure and characterization of ADA by ${ }^{1} \mathrm{H}$ NMR spectra and Fourier transform infrared spectra, effective hydrodynamic density of the film, modeling of QCM-D and ellipsometry data, optimization of the optical models, AFM height images, and stability of the cross-linked multilayered film (PDF)

\section{AUTHOR INFORMATION}

\section{Corresponding Author}

*E-mail: esth@kemi.dtu.dk. Phone: (+45) 45252439.

\section{ORCID $\odot$}

Junhao Huang: 0000-0002-9273-3695

Saeed Zajforoushan Moghaddam: 0000-0002-6536-7490

Notes

The authors declare no competing financial interest.

\section{ACKNOWLEDGMENTS}

J.H. acknowledges a stipend from the Chinese Scholarship Council (CSC).

\section{REFERENCES}

(1) Richardson, J. J.; Bjornmalm, M.; Caruso, F. Multilayer assembly. Technology-driven layer-by-layer assembly of nanofilms. Science 2015, 348, No. aaa2491.

(2) Boudou, T.; Crouzier, T.; Ren, K.; Blin, G.; Picart, C. Multiple functionalities of polyelectrolyte multilayer films: new biomedical applications. Adv. Mater. 2010, 22, 441-467.

(3) Tanum, J.; Heo, J.; Hong, J. Spontaneous Biomacromolecule Absorption and Long-Term Release by Graphene Oxide. ACS Omega 2018, 3, 5903-5909.
(4) Quantin, P.; Colaço, E.; El Kirat, K.; Egles, C.; Ficheux, H.; Landoulsi, J. Layer-by-Layer Assembly of Nanosized Membrane Fractions for the Assessment of Cytochrome P450 Xenobiotic Metabolism. ACS Omega 2018, 3, 12535-12544.

(5) Decher, G. Fuzzy nanoassemblies toward layered polymeric multicomposites. Science 1997, 277, 1232-1237.

(6) Rydzek, G.; Ji, Q.; Li, M.; Schaaf, P.; Hill, J. P.; Boulmedais, F.; Ariga, K. Electrochemical nanoarchitectonics and layer-by-layer assembly: From basics to future. Nano Today 2015, 10, 138-167.

(7) Borges, J.; Mano, J. F. Molecular interactions driving the layerby-layer assembly of multilayers. Chem. Rev. 2014, 114, 8883-8942.

(8) Huang, J.; Li, J.; Feng, Y.; Xiang, F.; Wang, R.; Wu, J.; Yan, H.; Chen, K.; Zhou, Q.; Liu, Y. Investigation of modified sodium alginateAlkyl glycoside interactions in aqueous solutions and at the oil-water interface. RSC Adv. 2016, 6, 51068-51077.

(9) Yang, J.-S.; Xie, Y.-J.; He, W. Research progress on chemical modification of alginate: A review. Carbohydr. Polym. 2011, 84, 3339.

(10) Bhattarai, N.; Gunn, J.; Zhang, M. Chitosan-based hydrogels for controlled, localized drug delivery. Adv. Drug Delivery Rev. 2010, 62, 83-99.

(11) Sahariah, P.; Masson, M. Antimicrobial Chitosan and Chitosan Derivatives: A Review of the Structure-Activity Relationship. Biomacromolecules 2017, 3846

(12) Luo, Y.; Wang, Q. Recent development of chitosan-based polyelectrolyte complexes with natural polysaccharides for drug delivery. Int. J. Biol. Macromol. 2014, 64, 353-367.

(13) Paul, W.; Sharma, C. P. Chitosan and alginate wound dressings: a short review. Trends Biomater. Artif. Organs 2004, 18, 18-23.

(14) Li, Z.; Ramay, H. R.; Hauch, K. D.; Xiao, D.; Zhang, M. Chitosan-alginate hybrid scaffolds for bone tissue engineering. Biomaterials 2005, 26, 3919-3928.

(15) Bernkop-Schnürch, A.; Dünnhaupt, S. Chitosan-based drug delivery systems. Eur. J. Pharm. Biopharm. 2012, 81, 463-469.

(16) Yang, J.; Chen, J.; Pan, D.; Wan, Y.; Wang, Z. pH-sensitive interpenetrating network hydrogels based on chitosan derivatives and alginate for oral drug delivery. Carbohydr. Polym. 2013, 92, 719-725.

(17) Silva, J. M.; Caridade, S. G.; Costa, R. R.; Alves, N. M.; Groth, T.; Picart, C.; Reis, R. L.; Mano, J. F. pH Responsiveness of Multilayered Films and Membranes Made of Polysaccharides. Langmuir 2015, 31, 11318-11328.

(18) Hillberg, A. L.; Holmes, C. A.; Tabrizian, M. Effect of genipin cross-linking on the cellular adhesion properties of layer-by-layer assembled polyelectrolyte films. Biomaterials 2009, 30, 4463-4470.

(19) Xie, H.-G.; Li, X.-X.; Lv, G.-J.; Xie, W.-Y.; Zhu, J.; Luxbacher, T.; Ma, R.; Ma, X.-J. Effect of surface wettability and charge on protein adsorption onto implantable alginate-chitosan-alginate microcapsule surfaces. J. Biomed. Mater. Res., Part A 2010, 92, 1357-1365.

(20) Zhou, J.; Romero, G.; Rojas, E.; Ma, L.; Moya, S.; Gao, C. Layer by layer chitosan/alginate coatings on poly(lactide-coglycolide) nanoparticles for antifouling protection and Folic acid binding to achieve selective cell targeting. J. Colloid Interface Sci. 2010, $345,241-247$.

(21) Costa, N. L.; Sher, P.; Mano, J. F. Liquefied Capsules Coated with Multilayered Polyelectrolyte Films for Cell Immobilization. Adv. Eng. Mater. 2011, 13, B218-B224.

(22) Martins, G. V.; Mano, J. F.; Alves, N. M. Nanostructured selfassembled films containing chitosan fabricated at neutral $\mathrm{pH}$. Carbohydr. Polym. 2010, 80, 570-573.

(23) Yuan, W.; Dong, H.; Li, C. M.; Cui, X.; Yu, L.; Lu, Z.; Zhou, Q. $\mathrm{pH}$-controlled construction of chitosan/alginate multilayer film: characterization and application for antibody immobilization. Langmuir 2007, 23, 13046-13052.

(24) Martins, G. V.; Merino, E. G.; Mano, J. F.; Alves, N. M. Crosslink effect and albumin adsorption onto chitosan/alginate multilayered systems: an in situ QCM-D study. Macromol. Biosci. 2010, 10, 1444-1455.

(25) Hatami, J.; Silva, S.; Oliveira, M.; Costa, R.; Reis, R.; Mano, J. Multilayered Films Produced by Layer-by-Layer Assembly of 
Chitosan and Alginate as a Potential Platform for the Formation of Human Adipose-Derived Stem Cell aggregates. Polymers 2017, 9, 440. (26) Remunan-Lopez, C.; Bodmeier, R. Mechanical, water uptake and permeability properties of crosslinked chitosan glutamate and alginate films. J. Controlled Release 1997, 44, 215-225.

(27) Mi, F.-L.; Sung, H.-W.; Shyu, S.-S. Drug release from chitosanalginate complex beads reinforced by a naturally occurring crosslinking agent. Carbohydr. Polym. 2002, 48, 61-72.

(28) Chang, J.-J.; Lee, Y.-H.; Wu, M.-H.; Yang, M.-C.; Chien, C.-T. Electrospun anti-adhesion barrier made of chitosan alginate for reducing peritoneal adhesions. Carbohydr. Polym. 2012, 88, 13041312.

(29) Iwasaki, N.; Yamane, S.-T.; Majima, T.; Kasahara, Y.; Minami, A.; Harada, K.; Nonaka, S.; Maekawa, N.; Tamura, H.; Tokura, S.; et al. Feasibility of polysaccharide hybrid materials for scaffolds in cartilage tissue engineering: evaluation of chondrocyte adhesion to polyion complex fibers prepared from alginate and chitosan. Biomacromolecules 2004, 5, 828-833.

(30) Costa, R. R.; Testera, A. M.; Arias, F. J.; Rodriguez-Cabello, J. C.; Mano, J. F. Layer-by-layer film growth using polysaccharides and recombinant polypeptides: a combinatorial approach. J. Phys. Chem. B 2013, 117, 6839-6848.

(31) Correia, C. R.; Sher, P.; Reis, R. L.; Mano, J. F. Liquefied chitosan-alginate multilayer capsules incorporating poly(1-lactic acid) microparticles as cell carriers. Soft Matter 2013, 9, 2125-2130.

(32) Caridade, S. G.; Monge, C.; Gilde, F.; Boudou, T.; Mano, J. F.; Picart, C. Free-standing polyelectrolyte membranes made of chitosan and alginate. Biomacromolecules 2013, 14, 1653-1660.

(33) Lawrie, G.; Keen, I.; Drew, B.; Chandler-Temple, A.; Rintoul, L.; Fredericks, P.; Grøndahl, L. Interactions between alginate and chitosan biopolymers characterized using FTIR and XPS. Biomacromolecules 2007, 8, 2533-2541.

(34) Wen, C.; Wan, M.; Li, X.; He, Q.; Gao, L.; Fang, W. Formation Mechanism and Properties of Polyelectrolyte Multilayer-Supported Lipid Bilayers: A Coarse-Grained Molecular Dynamics Study. ACS Omega 2017, 2, 910-917.

(35) Aston, R.; Wimalaratne, M.; Brock, A.; Lawrie, G.; Grondahl, L. Interactions between Chitosan and Alginate Dialdehyde Biopolymers and Their Layer-by-Layer Assemblies. Biomacromolecules 2015, 16, 1807-1817.

(36) Crouzier, T.; Boudou, T.; Picart, C. Polysaccharide-based polyelectrolyte multilayers. Curr. Opin. Colloid Interface Sci. 2010, 15, 417-426.

(37) Richert, L.; Engler, A. J.; Discher, D. E.; Picart, C. Elasticity of native and cross-linked polyelectrolyte multilayer films. Biomacromolecules 2004, 5, 1908-1916.

(38) Picart, C.; Schneider, A.; Etienne, O.; Mutterer, J.; Schaaf, P.; Egles, C.; Jessel, N.; Voegel, J. C. Controlled degradability of polysaccharide multilayer films in vitro and in vivo. Adv. Funct. Mater. 2005, 15, 1771-1780.

(39) Alves, N. M.; Picart, C.; Mano, J. F. Self assembling and crosslinking of polyelectrolyte multilayer films of chitosan and alginate studied by QCM and IR spectroscopy. Macromol. Biosci. 2009, 9, $776-785$.

(40) Hsien, T.-Y.; Rorrer, G. L. Heterogeneous cross-linking of chitosan gel beads: kinetics, modeling, and influence on cadmium ion adsorption capacity. Ind. Eng. Chem. Res. 1997, 36, 3631-3638.

(41) Silva, J. M.; Caridade, S. G.; Oliveira, N. M.; Reis, R. L.; Mano, J. F. Chitosan-alginate multilayered films with gradients of physicochemical cues. J. Mater. Chem. B 2015, 3, 4555-4568.

(42) Dai, J.; Jensen, A. W.; Mohanty, D. K.; Erndt, J.; Bruening, M. L. Controlling the permeability of multilayered polyelectrolyte films through derivatization, cross-linking, and hydrolysis. Langmuir 2001, 17, 931-937.

(43) Gendler, E.; Gendler, S.; Nimni, M. Toxic reactions evoked by glutaraldehyde-fixed pericardium and cardiac valve tissue bioprosthesis. J. Biomed. Mater. Res. 1984, 18, 727-736.
(44) Bigi, A.; Cojazzi, G.; Panzavolta, S.; Rubini, K.; Roveri, N. Mechanical and thermal properties of gelatin films at different degrees of glutaraldehyde crosslinking. Biomaterials 2001, 22, 763-768.

(45) Gough, J. E.; Scotchford, C. A.; Downes, S. Cytotoxicity of glutaraldehyde crosslinked collagen/poly (vinyl alcohol) films is by the mechanism of apoptosis. J. Biomed. Mater. Res. 2002, 61, 121130.

(46) Guthrie, R. The "Dialdehydes" from the Periodate Oxidation of Carbohydrates. Advances in Carbohydrate Chemistry; Elsevier, 1962; Vol. 16, pp 105-158.

(47) Kristiansen, K. A.; Potthast, A.; Christensen, B. E. Periodate oxidation of polysaccharides for modification of chemical and physical properties. Carbohydr. Res. 2010, 345, 1264-1271.

(48) Sprung, M. A. A Summary of the Reactions of Aldehydes with Amines. Chem. Rev. 1940, 26, 297-338.

(49) Cordes, E. H.; Jencks, W. P. On the Mechanism of Schiff Base Formation and Hydrolysis. J. Am. Chem. Soc. 1962, 84, 832-837.

(50) Jia, Y.; Li, J. Molecular Assembly of Schiff Base Interactions: Construction and Application. Chem. Rev. 2015, 115, 1597-1621.

(51) Jia, Y.; Fei, J.; Cui, Y.; Yang, Y.; Gao, L.; Li, J. pH-responsive polysaccharide microcapsules through covalent bonding assembly. Chem. Commun. 2011, 47, 1175-1177.

(52) Wang, J.; Fu, W.; Zhang, D.; Yu, X.; Li, J.; Wan, C. Evaluation of novel alginate dialdehyde cross-linked chitosan/calcium polyphosphate composite scaffolds for meniscus tissue engineering. Carbohydr. Polym. 2010, 79, 705-710.

(53) Zhao, X.; Chen, S.; Lin, Z.; Du, C. Reactive electrospinning of composite nanofibers of carboxymethyl chitosan cross-linked by alginate dialdehyde with the aid of polyethylene oxide. Carbohydr. Polym.. 2016, 148, 98-106.

(54) Liang, Y.; Liu, W.; Han, B.; Yang, C.; Ma, Q.; Song, F.; Bi, Q. An in situ formed biodegradable hydrogel for reconstruction of the corneal endothelium. Colloids Surf., B 2011, 82, 1-7.

(55) Mu, B.; Lu, C.; Liu, P. Disintegration-controllable stimuliresponsive polyelectrolyte multilayer microcapsules via covalent layerby-layer assembly. Colloids Surf., B 2011, 82, 385-390.

(56) Tauk, L.; Schröder, A. P.; Decher, G.; Giuseppone, N. Hierarchical functional gradients of $\mathrm{pH}$-responsive self-assembled monolayers using dynamic covalent chemistry on surfaces. Nat. Chem. 2009, 1, 649-656.

(57) Saito, H.; Hoffman, A. S.; Ogawa, H. I. Delivery of Doxorubicin from Biodegradable PEG Hydrogels Having Schiff Base Linkages $\dagger$. J. Bioact. Compat. Polym. 2007, 22, 589-601.

(58) Borch, R. F.; Bernstein, M. D.; Durst, H. D. Cyanohydridoborate anion as a selective reducing agent. J. Am. Chem. Soc. 1971, 93, 2897-2904.

(59) Tian, M.; Chen, X.; Li, H.; Ma, L.; Gu, Z.; Qi, X.; Li, X.; Tan, H.; You, C. Long-term and oxidative-responsive alginate-deferoxamine conjugates with a low toxicity for iron overload. RSC Adv. 2016, 6, 32471-32479.

(60) Gomez, C. G.; Rinaudo, M.; Villar, M. A. Oxidation of sodium alginate and characterization of the oxidized derivatives. Carbohydr. Polym. 2007, 67, 296-304.

(61) Pawar, S. N.; Edgar, K. J. Alginate derivatization: a review of chemistry, properties and applications. Biomaterials 2012, 33, 32793305.

(62) Reviakine, I.; Johannsmann, D.; Richter, R. P. Hearing what you cannot see and visualizing what you hear: interpreting quartz crystal microbalance data from solvated interfaces. Anal. Chem. 2011, 83, 8838-8848.

(63) Liu, X.; Dedinaite, A.; Rutland, M.; Thormann, E.; Visnevskij, C.; Makuska, R.; Claesson, P. M. Electrostatically anchored branched brush layers. Langmuir 2012, 28, 15537-15547.

(64) Lundin, M.; Solaqa, F.; Thormann, E.; Macakova, L.; Blomberg, E. Layer-by-layer assemblies of chitosan and heparin: effect of solution ionic strength and $\mathrm{pH}$. Langmuir 2011, 27, 7537-7548.

(65) Voinova, M. V.; Rodahl, M.; Jonson, M.; Kasemo, B. Viscoelastic acoustic response of layered polymer films at fluid-solid 
interfaces continuum mechanics approach. Phys. Scr. 1999, 59, 391396.

(66) Garg, A.; Heflin, J. R.; Gibson, H. W.; Davis, R. M. Study of Film Structure and Adsorption Kinetics of Polyelectrolyte Multilayer Films Effect of $\mathrm{pH}$ and Polymer Concentration. Langmuir 2008, 24, 10887-10894.

(67) Ramos, J. J. I.; Stahl, S.; Richter, R. P.; Moya, S. E. Water Content and Buildup of Poly(diallyldimethylammonium chloride)/ Poly(sodium 4-styrenesulfonate) and Poly(allylamine hydrochloride)/Poly(sodium 4-styrenesulfonate) Polyelectrolyte Multilayers Studied by an in Situ Combination of a Quartz Crystal Microbalance with Dissipation Monitoring and Spectroscopic Ellipsometry. Macromolecules 2010, 43, 9063-9070.

(68) Ramos, J. J. I.; Moya, S. E. Water content of hydrated polymer brushes measured by an in situ combination of a quartz crystal microbalance with dissipation monitoring and spectroscopic ellipsometry. Macromol. Rapid Commun. 2011, 32, 1972-1978.

(69) Ogieglo, W.; Wormeester, H.; Eichhorn, K.-J.; Wessling, M.; Benes, N. E. In situ ellipsometry studies on swelling of thin polymer films: A review. Prog. Polym. Sci. 2015, 42, 42-78.

(70) Halthur, T. J.; Elofsson, U. M. Multilayers of charged polypeptides as studied by in situ ellipsometry and quartz crystal microbalance with dissipation. Langmuir 2004, 20, 1739-1745.

(71) Höök, F.; Kasemo, B.; Nylander, T.; Fant, C.; Sott, K.; Elwing, $\mathrm{H}$. Variations in coupled water viscoelastic properties and film thickness of a Mefp-1 protein film during adsorption and cross-linking a quartz crystal microbalance with dissipation monitoring ellipsometry. Anal. Chem. 2001, 73, 5796-5804.

(72) Daviero, G. J.; Roberts, P. J. W.; Maile, K. Refractive index matching in large-scale stratified experiments. Exp. Fluids 2001, 31, $119-126$.

(73) Cathell, M. D.; Schauer, C. L. Structurally colored thin films of $\mathrm{Ca}^{2+}$-cross-linked alginate. Biomacromolecules 2007, 8, 33-41.

(74) Azofeifa, D. E.; Arguedas, H. J.; Vargas, W. E. Optical properties of chitin and chitosan biopolymers with application to structural color analysis. Opt. Mater. 2012, 35, 175-183.

(75) Picheth, G. F.; Sierakowski, M. R.; Woehl, M. A.; Pirich, C. L.; Schreiner, W. H.; Pontarolo, R.; de Freitas, R. A. Characterisation of ultra-thin films of oxidised bacterial cellulose for enhanced anchoring and build-up of polyelectrolyte multilayers. Colloid Polym. Sci. 2014, 292, 97-105.

(76) Wong, A. K.; Krull, U. J. Surface characterization of 3glycidoxypropyltrimethoxysilane films on silicon-based substrates. Anal. Bioanal. Chem. 2005, 383, 187-200.

(77) Liu, C.; Thormann, E.; Claesson, P. M.; Tyrode, E. Surface grafted chitosan gels. Part I. Molecular insight into the formation of chitosan and poly(acrylic acid) multilayers. Langmuir 2014, 30, $8866-8877$.

(78) Wong, A. K.; Krull, U. J. Surface characterization of 3glycidoxypropyltrimethoxysilane films on silicon-based substrates. Anal. Bioanal. Chem. 2005, 383, 187-200.

(79) Liu, C.; Thormann, E.; Claesson, P. M.; Tyrode, E. Surface grafted chitosan gels. Part II. Gel formation and characterization. Langmuir 2014, 30, 8878-8888.

(80) McAloney, R. A.; Sinyor, M.; Dudnik, V.; Goh, M. C. Atomic force microscopy studies of salt effects on polyelectrolyte multilayer film morphology. Langmuir 2001, 17, 6655-6663.

(81) Lavalle, P.; Gergely, C.; Cuisinier, F. J. G.; Decher, G.; Schaaf, P.; Voege, J. C.; Picart, C. Comparison of the structure of polyelectrolyte multilayer films exhibiting a linear and an exponential growth regime an in situ atomic force microscopy study. Macromolecules 2002, 35, 4458-4465.

(82) Bodvik, R.; Thormann, E.; Karlson, L.; Claesson, P. M. Temperature-dependent adsorption of cellulose ethers on silica and hydrophobized silica immersed in aqueous polymer solution. RSC Adv. 2011, 1, 305.

(83) Höök, F.; Vörös, J.; Rodahl, M.; Kurrat, R.; Böni, P.; Ramsden, J. J.; Textor, M.; Spencer, N. D.; Tengvall, P.; Gold, J.; Kasemo, B. A comparative study of protein adsorption on titanium oxide surfaces using in situ ellipsometry, optical waveguide lightmode spectroscopy, and quartz crystal microbalance/dissipation. Colloids Surf., B 2002, 24, $155-170$.

(84) Bittrich, E.; Rodenhausen, K. B.; Eichhorn, K.-J.; Hofmann, T.; Schubert, M.; Stamm, M.; Uhlmann, P. Protein adsorption on and swelling of polyelectrolyte brushes: A simultaneous ellipsometryquartz crystal microbalance study. Biointerphases 2010, 5, 159-167.

(85) Laschitsch, A.; Menges, B.; Johannsmann, D. Simultaneous determination of optical and acoustic thicknesses of protein layers using surface plasmon resonance spectroscopy and quartz crystal microweighing. Appl. Phys. Lett. 2000, 77, 2252-2254.

(86) Fujiwara, H. Spectroscopic Ellipsometry: Principles and Applications; John Wiley \& Sons, 2007.

(87) Tompkins, H. G.; Hilfiker, J. N. Spectroscopic Ellipsometry: Practical Application to Thin Film Characterization; Momentum Press, 2015.

(88) Xin, Y.; Yuan, J. Schiff's base as a stimuli-responsive linker in polymer chemistry. Polym. Chem. 2012, 3, 3045-3055.

(89) Corbett, P. T.; Leclaire, J.; Vial, L.; West, K. R.; Wietor, J.-L.; Sanders, J. K.; Otto, S. Dynamic combinatorial chemistry. Chem. Rev. 2006, 106, 3652-3711.

(90) Rowan, S. J.; Cantrill, S. J.; Cousins, G. R.; Sanders, J. K.; Stoddart, J. F. Dynamic covalent chemistry. Angew. Chem., Int. Ed. 2002, 41, 898-952.

(91) Jencks, W. P. Studies on the Mechanism of Oxime and Semicarbazone Formation1. J. Am. Chem. Soc. 1959, 81, 475-481.

(92) Conant, J. B.; Bartlett, P. D. A Quantitative Study of Semicarbazone Formation. J. Am. Chem. Soc. 1932, 54, 2881-2899.

(93) Hutchins, R. O.; Hutchins, M. K. Reduction of $\mathrm{C}=\mathrm{N}$ to CHNH by metal hydrides. Compr. Org. Synth. 1991, 8, 25.

(94) Clinton, F. Sodium cyanoborohydride-a highly selective reducing agent for organic functional groups. Synthesis 1975, 3, 135146.

(95) Jentoft, N.; Dearborn, D. G. Labeling of proteins by reductive methylation using sodium cyanoborohydride. J. Biol. Chem. 1979, 254, 4359-4365.

(96) Liu, C.; Thormann, E.; Tyrode, E.; Claesson, P. M. Charge regulation and energy dissipation while compressing and sliding a cross-linked chitosan hydrogel layer. J. Colloid Interface Sci. 2015, 443, $162-169$.

(97) Tokarev, I.; Minko, S. Stimuli-responsive hydrogel thin films. Soft Matter 2009, 5, 511-524.

(98) Yuk, H.; Zhang, T.; Lin, S.; Parada, G. A.; Zhao, X. Tough bonding of hydrogels to diverse non-porous surfaces. Nat. Mater. 2016, 15, 190-196.

(99) Lee, K. Y.; Mooney, D. J. Alginate: properties and biomedical applications. Prog. Polym. Sci. 2012, 37, 106-126.

(100) Dunér, G.; Thormann, E.; Ramström, O.; Dèdinaitè, A. Letter to the Editor: Friction between Surfaces-Polyacrylic Acid Brush and Silica-Mediated by Calcium Ions. J. Dispersion Sci. Technol. 2010, 31, $1285-1287$. 